\title{
UAV PHOTOGRAMMETRY FOR MAPPING AND MONITORING OF NORTHERN PERMAFROST LANDSCAPES
}

\author{
R. H. Fraser ${ }^{\text {a, * }}$, I. Olthof ${ }^{a}$, M. Maloley ${ }^{a}$, R. Fernandes ${ }^{a}$, C. Prevost ${ }^{a}$, J. van der Sluijs ${ }^{b}$ \\ ${ }^{a}$ Canada Centre for Mapping and Earth Observation, Natural Resources Canada, 560 Rochester St., Ottawa, Canada - \\ (Robert.Fraser, Ian.Olthof, Matthew.Maloley, Richard.Fernandes, Christian.Prevost)@ NRCan.gc.ca \\ ${ }^{\mathrm{b}}$ NWT Centre for Geomatics - Informatics, Government of the Northwest Territories, 4923-52 ${ }^{\text {nd }}$ street, Yellowknife, Canada - \\ Jurjen_vanderSluijs@gov.nt.ca
}

KEY WORDS: Unmanned Aerial Vehicles, UAVs, Mapping, Arctic, Disturbance, Permafrost, Structure from motion

\begin{abstract}
:
Northern environments are changing in response to recent climate warming, resource development, and natural disturbances. The Arctic climate has warmed by $2-3^{\circ} \mathrm{C}$ since the 1950 's, causing a range of cryospheric changes including declines in sea ice extent, snow cover duration, and glacier mass, and warming permafrost. The terrestrial Arctic has also undergone significant temperaturedriven changes in the form of increased thermokarst, larger tundra fires, and enhanced shrub growth. Monitoring these changes to inform land managers and decision makers is challenging due to the vast spatial extents involved and difficult access.

Environmental monitoring in Canada's North is often based on local-scale measurements derived from aerial reconnaissance and photography, and ecological, hydrologic, and geologic sampling and surveying. Satellite remote sensing can provide a complementary tool for more spatially comprehensive monitoring but at coarser spatial resolutions. Satellite remote sensing has been used to map Arctic landscape changes related to vegetation productivity, lake expansion and drainage, glacier retreat, thermokarst, and wildfire activity. However, a current limitation with existing satellite-based techniques is the measurement gap between field measurements and high resolution satellite imagery. Bridging this gap is important for scaling up field measurements to landscape levels, and validating and calibrating satellite-based analyses. This gap can be filled to a certain extent using helicopter or fixed-wing aerial surveys, but at a cost that is often prohibitive.
\end{abstract}

Unmanned aerial vehicle (UAV) technology has only recently progressed to the point where it can provide an inexpensive and efficient means of capturing imagery at this middle scale of measurement with detail that is adequate to interpret Arctic vegetation (i.e. $1-5 \mathrm{~cm}$ ) and coverage that can be directly related to satellite imagery $\left(1-10 \mathrm{~km}^{2}\right)$. Unlike satellite measurements, UAVs permit frequent surveys (e.g. for monitoring vegetation phenology, fires, and hydrology), are not constrained by repeat cycle or cloud cover, can be rapidly deployed following a significant event, and are better suited than manned aircraft for mapping small areas. UAVs are becoming more common for agriculture, law enforcement, and marketing, but their use in the Arctic is still rare and represents untapped technology for northern mapping, monitoring, and environmental research.

We are conducting surveys over a range of sensitive or changing northern landscapes using a variety of UAV multicopter platforms and small sensors. Survey targets include retrogressive thaw slumps, tundra shrub vegetation, recently burned vegetation, road infrastructure, and snow. Working with scientific partners involved in northern monitoring programs (NWT CIMP, CHARS, NASA ABOVE, NRCan-GSC) we are investigating the advantages, challenges, and best practices for acquiring high resolution imagery from multicopters to create detailed orthomosaics and co-registered 3D terrain models. Colour and multispectral orthomosaics are being integrated with field measurements and satellite imagery to conduct spatial scaling of environmental parameters. Highly detailed digital terrain models derived using structure from motion ( $\mathrm{SfM}$ ) photogrammetry are being applied to measure thaw slump morphology and change, snow depth, tundra vegetation structure, and surface condition of road infrastructure.

These surveys and monitoring applications demonstrate that UAV-based photogrammetry is poised to make a rapid contribution to a wide range of northern monitoring and research applications.

\footnotetext{
* Corresponding author
} 